\title{
Diels-Alder Reactions of Thiophene Oxides Generated in situ
}

\author{
KURT TORSSELL
}

Department of Organic Chemistry, University of Aarhus, DK-8000 Aarhus C, Denmark

Dedicated to Professor Karl Myrbäck on his 75th birthday

Oxidation of thiophenes with $m$-Cl-perbenzoic acid in the presence of quinones gives sulfoxidebridged adducts and naphtho- or anthraquinones. Benzoquinone and thiophene give unexpectedly juglone in a yield of $c a .20 \%$ among other products. Thiophene sulfoxide is a very unstable and reactive intermediate.

By engaging the lone pairs of the thiophene sulfur in bond formation, the aromatic stabilization is destroyed and the double bonds receive more diene character. This is borne out in the properties of thiophene sulfoxide ${ }^{1}$ and thiophene sulfone ${ }^{2}$ which are unstable and have not been prepared in a pure state. They dimerize in a Diels-Alder fashion (1) and have thus both ene and diene properties. ${ }^{3}$ A few stable substituted thiophene sulfones have been prepared." It therefore seemed reasonable to anticipate the formation of Diels-Alder adducts when the sulfoxide was generated in presence of suitable enes.

Thiophene was treated with two equivalents of $m$-chloroperbenzoic acid in methylene chloride at $0{ }^{\circ} \mathrm{C}$ for $48 \mathrm{~h}$ in the presence of phenylacetylene, ethyl propiolate, or acrylonitrile, but none of the expected cyclic derivatives were obtained. A reaction occurred with quinones but it took a somewhat unexpected course. The major product from benzoquinone, thiophene, and $m$-chloroperbenzoic acid (1:1:2.4) was juglone $1(21 \%)$, naphthoquinone 2 , and traces of a compound thought to be acylated juglone. The presence of the adduct 3 was proved spectroscopically in the crude product. It was isolated in a pure condition (ca. $20 \%$ ) by using chloroform as the reaction medium. When thiophene was oxidized separately at
$0{ }^{\circ} \mathrm{C}$ overnight and benzoquinone then added, no adduct or naphthoquinones could be detected, which shows that thiophene sulfoxide is shortlived and reactive even at $0^{\circ} \mathrm{C}$. There is a competition between $S$ - and $C$-hydroxylation. The latter occurs at an early stage of the reaction since naphthoquinone is stable to the peracid under the reaction conditions. $3 \mathrm{de}$ composed slowly on standing, forming 2 as one of the products, but no juglone 1 could be detected by TLC. Refluxing 3 in chloroform in the presence of $m$-chlorobenzoic acid did not produce juglone, i.e., it is not formed via a Pummerer rearrangement but it was slowly formed together with naphthoquinone (2:1) by the action of peracid on 3 at $0^{\circ} \mathrm{C}$. Alternatively, juglone could arise from the Diels-Alder reaction of 2-hydroxy (or benzoyloxy) thiophene oxide. 2,5-Dimethylthiophene gives a stable sulfone, which was found to react very slowly with benzoquinone at room temp. Refluxing in chloroform overnight was necessary to bring about the formation of 6 . When 2,5dimethylthiophene was oxidized at $0{ }^{\circ} \mathrm{C}$ in the presence of benzoquinone, the adduct $4 a$ was obtained in a yield of $33 \%$ but neither 2,5-dimethylthiophene sulfone nor 6 could be detected in the crude reaction mixture, i.e., the thiophene sulfoxides are much more reactive enophiles than are the sulfones and furthermore, the naphthoquinones produced are not formed by initial oxidation of the thiophene to the sulfone followed by Diels. Alder addition and splitting off sulfur dioxide. 6 was stable in the presence of trifluoroacetic acid but decomposed in contact with silica and in basic solution forming $5 a$ as one of the products. Prolonged refluxing of 6 in chloro-

Acta Chem. Scand. B 30 (1976) No. 4 


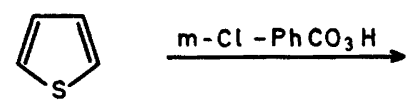<smiles>CC12C=CSC1(O)C1C=CC2C1([O-])O</smiles>

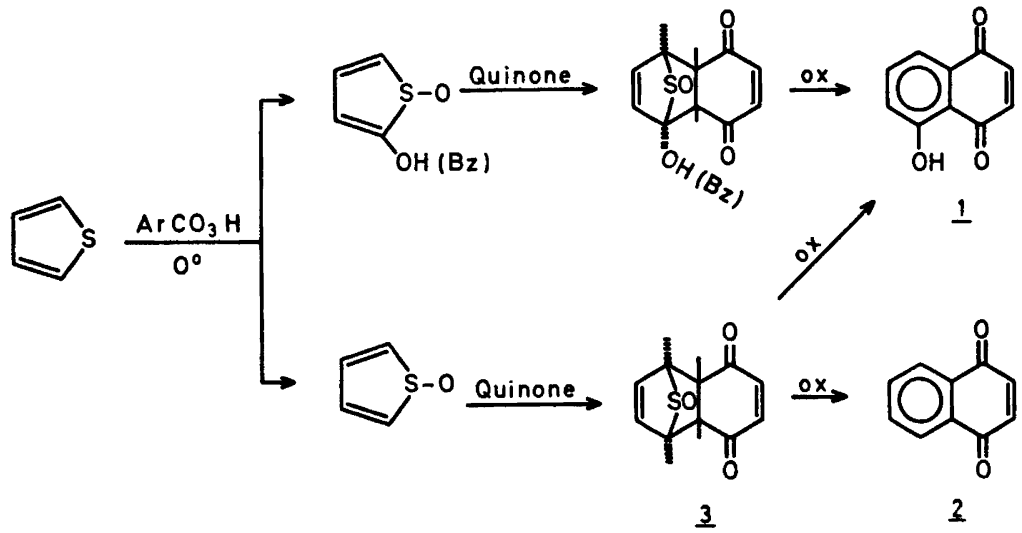

form gave $5 a$, whereas under these conditions $4 a$ is practically not affected. After $5 \mathrm{~h}$ reflux of $4 a$ in toluene only ca. $18 \%$ of $4 a$ decomposed. Thus the sulfone bridge is considerably more unstable than the sulfoxide bridge, a circumstance that was noted earlier. 2," The possibility remains that the naphthoquinones are formed via an oxidation of the sulfoxide bridge to a sulfone function. The most plausible routes to the naphthoquinones are depicted in (2).

From toluquinone a mixture (crude yield ca. $30 \%$ ) was obtained of 2-methylnaphthoquinone and its 5- and/or 8-hydroxylated derivatives which were difficult to separate.

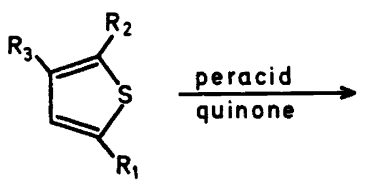

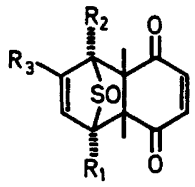

$\underline{4 a-c}$<smiles>[R]c1cc([R])c2c(c1[R2])C(=O)C=CC2=O</smiles>

$\underline{5 a-e}$

$4 a, 5 a \quad \mathbf{R}_{1}=\mathrm{R}_{2}=\mathrm{CH}_{3} ; \mathrm{R}_{3}=\mathrm{H}$

$4 b, 5 b \quad \mathrm{R}_{1}=\mathrm{CH}_{3} ; \mathrm{R}_{2}=\mathrm{R}_{3}=\mathrm{H}$

$4 c$, 5c $\mathrm{R}_{1}=\mathrm{R}_{2}=\mathrm{H} ; \mathrm{R}_{3}=\mathrm{CH}_{3}$

5d $\mathrm{R}_{1}=\mathrm{CH}_{3} ; \mathrm{R}_{2}=\mathrm{OH} ; \mathrm{R}_{3}=\mathrm{H}$

5e $\mathrm{R}_{1}=\mathrm{H} ; \mathrm{R}_{2}=\mathrm{OH} ; \mathrm{R}_{3}=\mathrm{CH}_{3}$

4f, sf $\quad \mathbf{R}_{1}=\mathrm{R}_{2}=\mathrm{Cl} ; \mathrm{R}_{3}=\mathrm{H}$

5g $\quad \mathbf{R}_{1}=\mathbf{R}_{2}=\mathrm{Ph} ; \mathrm{R}_{3}=\mathrm{H}$<smiles>Cc1ccc(C)s1</smiles><smiles>O=C1C=CC(=O)C=C1</smiles><smiles>CC[GeH2]C(C)(C)C</smiles>

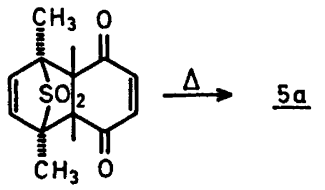

6

Acta Chem. Scand. B 30 (1976) No. 4 
Addition to the methyl side of toluquinone was not observed.

A series of substituted thiophenes were oxidized in the presence of benzoquinone as dienophile. 2-Carbomethoxy-, 2,4-diphenyl, and 2-phenylthiophene gave no adducts, but small amounts of the corresponding naphthoquinones could be isolated from 2,5-diphenyl- and 2,5dichlorothiophene. The oxidation of thiophenes with electron withdrawing groups is slow. Better yield of the adducts $(4 a-c)$ was obtained from the methylated thiophenes.

Following the principle of maximal $\pi$-orbital in the transition state of the diene reaction, the adduct was given the configuration depicted in (3). This is in agreement with the NMR data for 3. In similar systems, ${ }^{5} J_{1.2 \text { (exo) }} 3-4 \mathrm{~Hz}$ and $J_{1,2 \text { (endo) }} \sim 0 \mathrm{~Hz}$. The configuration of the SO group is unknown. Only one isomer was obtained except in the reactions with 3-methylthiophene, where the NMR spectrum of the crude product indicated the presence of two isomeric products $(\sim 10: 1)$, of which only the most abundant one was isolated in a pure condition.

Naphthoquinone, thiophene, and peracid gave anthraquinone, $7 a$ (25 or $58 \%$, based upon recovered naphthoquinone), but no 1 hydroxyanthraquinone could be isolated. The methyl substituted thiophenes gave anthraquinones, $7 b-7 c$, in a total yield of $c a .10-$ $20 \%$, and also some hydroxylated derivatives. Considerable amounts of adducts with the sulfoxide bridge retained were also formed (NMR), but they decomposed slowly to intractable material and were not isolated in a pure state.

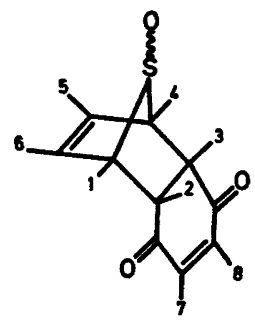

$\underline{3}$

$\mathrm{J}_{1,2}=4.0 \mathrm{~Hz} ; \mathrm{J}_{2,5} \sim \mathrm{J}_{2,6} \sim \mathrm{J}_{2,7} \sim 0 \mathrm{~Hz}$

$\mathrm{J}_{2.3}=8.7 \mathrm{~Hz} ; \mathrm{J}_{1.3} \sim \mathrm{J}_{1.4} \sim 0 . \mathrm{J}_{2.7} \sim \mathrm{Hz}$

$J_{1,5}=0.9 \mathrm{~Hz}$

$\mathrm{J}_{1.6}=4.8 \mathrm{~Hz}$

$J_{5,6}^{1.6}=10.2 \mathrm{~Hz}$

Acta Chem. Scand. B 30 (1976) No. 4

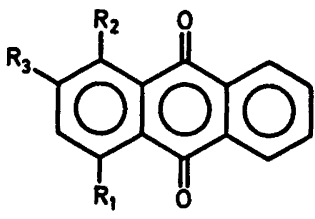

$7 a \quad \mathrm{R}_{1}=\mathrm{R}_{2}=\mathrm{R}_{3}=\mathrm{H}$

7b $\mathrm{R}_{1}=\mathrm{R}_{3}=\mathrm{H} ; \mathrm{R}_{2}=\mathrm{CH}_{3}$

7c $\mathrm{R}_{1}=\mathrm{R}_{2}=\mathrm{H} ; \mathrm{R}_{3}=\mathrm{CH}_{3}$

\section{EXPERIMENTAL}

Juglone, 1, naphthoquinone, 2, and adduct 3. A mixture of thiophene $(0.84 \mathrm{~g}, 10 \mathrm{mmol})$, benzoquinone $(1.08 \mathrm{~g}, 10 \mathrm{mmol})$, and $m$-chloroperbenzoic acid $(5.0 \mathrm{~g}, c a .81 \%, 25 \mathrm{mmol})$ in methylene chloride $(35 \mathrm{ml})$ was stirred for 2 days at $0{ }^{\circ} \mathrm{C}$. The precipitated $m$-chlorobenzoic acid was filtered off, the solution washed with aqueous sodium bicarbonate, dried over sodium sulfate, and evaporated in vacuo. Ethanol $(4 \mathrm{ml})$ was added and the solu. tion was left standing in the freezer $\left(-15^{\circ} \mathrm{C}\right)$ overnight. $1(320 \mathrm{mg})$ precipitated, contam. inated with 2 (ca. $10 \%$ ). A second crop of crystals $(180 \mathrm{mg}$ ) could be obtained by partial evaporation of the filtrate consisting of 1 (ca. $40 \%), 2(40 \%)$, and benzoquinone $(20 \%$, NMR). The yields of juglone and naphthoquinone were 21 and $7 \%$, respectively. The identity of juglone was yerified by comparison with an authentic sample. The NMR spectrum of the crude reaction product showed the presence of the adduct 3. Preparative TLC of a sample of the crude product gave also a small fraction which according to the IR spectrum appeared to be $m$-chlorobenzoyl juglone. It was not investigated further.

Preparation of the adducts, 3, 4b, and 4c. Chloroform was used as solvent for the thiophene oxidation described above. The same work-up method was followed. Acetonitrile $(1 \mathrm{ml})$ and then ether $(12 \mathrm{ml})$ were added to the crude product obtained after evaporation of the chloroform. $3(0.44 \mathrm{~g}, 21 \%)$ precipitated as dark-brown crystals after standing overnight in the freezer. 3 was purified by dissolv. ing in acetonitrile $(2 \mathrm{ml})$ and precipitation with ether, m.p. $129{ }^{\circ} \mathrm{C}$, brown crystals. (Found: C 57.69; $\mathrm{H}$ 3.97. Calc. for $\mathrm{C}_{10} \mathrm{H}_{8} \mathrm{SO}_{3}$ : C 57.69; H 3.84). NMR ( $\left.\mathrm{CDCl}_{3}\right): \delta 3.99(2 \mathrm{H}$, distorted $\mathrm{t})$, 4.31 (2 H, m), 6.20 (2 H, distorted t), 6.79 $(2 \mathrm{H}, \mathrm{s})$. Evaporation of the ether filtrate and chromatography of the remainder on silica gave $0.2 \mathrm{~g}$ of a mixture of 1 and 2 in the quinone fraction.

$4 b(24 \%)$ m.p. $133-135{ }^{\circ} \mathrm{C}$, and $4 c(18 \%)$ m.p. $124-126{ }^{\circ} \mathrm{C}$, were prepared from 2 . methylthiophene and 3-methylthiophene, respectively, according to the same procedure. (Found for $4 b$ : C 59.35; H 4.55. Found for $4 c$ : C 58.78; $\mathrm{H}$ 4.60. Calc. for $\mathrm{C}_{11} \mathrm{H}_{10} \mathrm{SO}_{3}$ : C 59.45; 
H 4.50). NMR $\left(\mathrm{CDCl}_{3}\right), 4 b: \delta 1.75(3 \mathrm{H}, \mathrm{s}$, 3.5 (1 H, d), $4.1(2 \mathrm{H}, \mathrm{m}), 6.16(2 \mathrm{H}, \mathrm{m}), 6.73$ $(2 \mathrm{H}, \mathrm{s})$. NMR $\left(\mathrm{CDCl}_{3}\right), 4 c$ : $\delta 1.74(3 \mathrm{H}, \mathrm{d}$, $J=1.6 \mathrm{~Hz}), 3.9(2 \mathrm{H}, \mathrm{m}), 4.15(2 \mathrm{H}, \mathrm{m}), 5.77$ ( $1 \mathrm{H}, \mathrm{d}, \mathrm{t}, J=1.6$ and $4.3 \mathrm{~Hz}), 6.78(2 \mathrm{H}, \mathrm{s})$.

Evaporation of the ether filtrate and chro. matography on silica $\left(\mathrm{CHCl}_{3}\right.$ - light petroleum, $1: 1)$ gave a crude quinone fraction, $c a .0 .3-0.4 \mathrm{~g}$. 2-Methylthiophene gave 5-methylnaphthoquinone, $5 b,(90 \mathrm{mg})$, m.p. $119-122^{\circ} \mathrm{C}$ (lit." $121-122^{\circ} \mathrm{C}$ ) and 5-methyl-8-hydroxynaphthoquinone, $5 d,(40 \mathrm{mg})$, red-yellow needles, m.p. $160-163^{\circ} \mathrm{C}, \mathrm{NMR}\left(\mathrm{CDCl}_{3}\right), 5 d: \delta 2.61(3 \mathrm{H}, \mathrm{s})$, 7.15 and $7.43\left(2 \mathrm{H}, \mathrm{AB}\right.$-system, $\left.J_{\mathrm{AB}}=8.6 \mathrm{~Hz}\right)$. 3-Methylthiophene gave 6-methylnaphthoquinone, 5c, $(170 \mathrm{mg})$, m.p. $86-88^{\circ} \mathrm{C}$ (lit. ${ }^{8} 90-$ $\left.91{ }^{\circ} \mathrm{C}\right)$ and 5-hydroxy-6-methylnaphthoquinone, 5e (30 mg), m.p. $107-109^{\circ} \mathrm{C}$; UV (EtOH), $5 e: \lambda_{\max } 219,252,434, \varepsilon 4.20,4.13,3.62$; NMR $\left(\mathrm{CDCl}_{3}\right), 5 e: \delta 2.36(3 \mathrm{H}, \mathrm{s}), 6.94(2 \mathrm{H}, \mathrm{s}), 7.54$ (2 H, s); mol.weight 188 (MS).

The yields of the naphthoquinone derivatives were raised somewhat when the reaction was performed in chloroform, but the adducts were more difficult to isolate.

Preparation of adduct 4a. m-Cl-Perbenzoic acid (3.5 g, $80 \%$ ) were added to 2,5-dimethylthiophene $(2.3 \mathrm{~g})$ and benzoquinone $(2.15 \mathrm{~g})$ in methylene chloride $(50 \mathrm{ml})$ at $-10^{\circ} \mathrm{C}$. After $2 \mathrm{~h}$ at $0{ }^{\circ} \mathrm{C}$ a further portion of the peracid $(3.5 \mathrm{~g})$ was added and the mixture was stirred at $0{ }^{\circ} \mathrm{C}$ for $36 \mathrm{~h}$. The precipitated $\mathrm{m}$-Cl-benzoic acid was filtered off and the chloroform solution extracted twice with sodium bicarbonate solution, dried, and evaporated in vacuo. Addition of ethanol $(5 \mathrm{ml})$ and carbon tetrachloride $(10 \mathrm{ml})$ gave $5 a(1.3 \mathrm{~g})$ on cooling. Evaporation of the filtrate and preparative TLC of the remainder $\left(\mathrm{SiO}_{2}, \mathrm{CHCl}_{3}\right)$ gave another $0.2 \mathrm{~g}$ of $4 a$. The total yield was $33 \%$. $4 a$ was recrystallized from acetonitrile adding some ether to the solution, m.p. $139^{\circ} \mathrm{C}$. (Found: C 61.03; $\mathrm{H}$ 5.34. Calc. for $\mathrm{C}_{12} \mathrm{H}_{12} \mathrm{O}_{3} \mathrm{~S}$ : $\mathrm{C} 61.00 ; \mathrm{H} \mathrm{5.12)}$. NMR $\left(\mathrm{CDCl}_{3}\right): \delta 1.67(6 \mathrm{H}, \mathrm{s}), 3.58(2 \mathrm{H}, \mathrm{s})$, $6.04(2 \mathrm{H}, \mathrm{s}), 6.67(2 \mathrm{H}, \mathrm{s})$. The fast-going TLC fraction gave $100 \mathrm{mg}$ of the naphthoquinone 5a, m.p. $121-122^{\circ} \mathrm{C}$ (lit. ${ }^{\circ} 124-125^{\circ} \mathrm{C}$ ).

Preparation of 4 f and 5f. A mixture of 2,5dichlorothiophene $(1.5 \mathrm{~g}, 10 \mathrm{mmol})$, benzoquinone (1.1 g, $10 \mathrm{mmol})$, and $m$-chloroper. benzoic acid $(4.6 \mathrm{~g}, 80 \%, 23 \mathrm{mmol})$ in methylene chloride $(40 \mathrm{ml})$ was kept at room temp. for 2 days and then refluxed for $6 \mathrm{~h}$. After the usual work-up, a mixture of $4 f(40 \%)$ and $5 f$ $(60 \%)(0.2 \mathrm{~g})$ precipitated from the ethanolic solution $(5 \mathrm{ml})$ in the freezer. $5 f$ dissolved in carbon tetrachloride and was recrystallized from ethanol, yellow needles, m.p. $168-169^{\circ} \mathrm{C}$ (lit. $.^{10} 173-174^{\circ} \mathrm{C}$ ). $4 f$, which is sparely soluble in carbon tetrachloride, was recrystallized from acetonitrile, yellow cubes, dec. $135^{\circ} \mathrm{C}$. (Found: $\mathrm{C}$ 43.88; $\mathrm{H}$ 2.45. Calc. for $\mathrm{C}_{10} \mathrm{H}_{8} \mathrm{O}_{3} \mathrm{SCl}_{2}$ : C 43.34; $\mathrm{H} 2.17)$. NMR $\left(\mathrm{CDCl}_{3}\right): \delta 4.00(2 \mathrm{H}, \mathrm{s}), 6.36$ (2 $\mathrm{H}, \mathrm{s}), 6.84(2 \mathrm{H}, \mathrm{s})$.
5,8-Diphenylnaphthoquinone $5 \mathrm{~g}$ was obtained in a yield of $8 \%$ using the preceding method (reflux $2 \mathrm{~h}$ ) and preparative TLC of the crude reaction mixture from the work-up, m.p. $142-$ $143^{\circ} \mathrm{C}$ (lit.11 $141-142^{\circ} \mathrm{C}$ ).

Anthraquinone 7a. Naphthoquinone (1.58 g, $10 \mathrm{mmol})$, thiophene $(0.85 \mathrm{~g}, 10 \mathrm{mmol})$, and $m$-chloroperbenzoic acid $(5.5 \mathrm{~g}, 80 \%, 28 \mathrm{mmol})$ in methylene chloride were stirred for 2 days at $0^{\circ} \mathrm{C}$. After the usual work-up, methanol $(20 \mathrm{ml})$ was added to the remainder of the evaporated chloroform extract and from the cooled solution $0.6 \mathrm{~g} 7 a$, m.p. $284^{\circ} \mathrm{C}$, precipitated, identical with an authentic specimen. Naphthoquinone $(0.7 \mathrm{~g})$ was isolated by preparative TLC from the evaporated filtrate.

1-Methyl anthraquinone $7 \mathrm{~b}$. A stirred mixture of naphthoquinone $(1.58 \mathrm{~g}, 10 \mathrm{mmol})$, 1-methylthiophene $(1.0 \mathrm{~g}, 10 \mathrm{mmol})$, and $m$-chloroperbenzoic acid $(4.6 \mathrm{~g}, 80 \%, 23 \mathrm{mmol})$ in methylene chloride $(50 \mathrm{ml})$ at $0{ }^{\circ} \mathrm{C}, 2$ days, gave after usual work-up a crude product (the NMR spectrum showed the presence of considerable amounts of the adduct which was not isolated in a pure condition), which was chromatographed on silica $\left(\mathrm{CHCl}_{3}\right.$ - light petroleum, 2:1). The quinone fraction $(0.39 \mathrm{~g})$ contained $\boldsymbol{\gamma b}$ (ca. $70 \%$ ), naphthoquinone (ca. $30 \%$ ), and traces of a hydroxylated anthraquinone. $7 b$ was recrystallized from ethanol, m.p. 170$172{ }^{\circ} \mathrm{C}$ (lit. ${ }^{12} 171-173^{\circ} \mathrm{C}$ ).

2-Methylanthraquinone 7c was obtained in a similar manner from 3-methylthiophene. The chromatographed quinone fraction $(0.52 \mathrm{~g}$ from 3-methylthiophene $(1.0 \mathrm{~g})$, naphthoquinone $(1.6 \mathrm{~g})$ and perbenzoic acid $(4 \mathrm{~g}))$, contained $c a$. $65 \% 7 c, 35 \%$ naphthoquinone, and traces of a hydroxylated anthraquinone. Recrystallization from ethanol gave pure $7 c$, m.p. 177- 179 ${ }^{\circ} \mathrm{C}$ (lit. ${ }^{1 s} 178-179^{\circ} \mathrm{C}$ ).

2,5-Dimethylthiophene sulfone was prepared by oxidation of 2,5-dimethyl thiophene $(5 \mathrm{~g})$ with $m$-chloroperbenzoic acid (26 $\mathrm{g} \sim 70 \%$, ca. 2.3 eqv.) in methylene chloride $(100 \mathrm{ml})$ at $0{ }^{\circ} \mathrm{C}$ for $48 \mathrm{~h}$. The suspension was filtered and the filtrate washed with aqueous sodium bicarbonate. The solvent was evaporated. The product which solidified in the refrigerator could be recrystallized from methanol giving $2.2 \mathrm{~g}$ of pure sulfone. NMR $\left(\mathrm{CDCl}_{3}\right): \delta 2.10$ $(6 \mathrm{H}, \mathrm{d}, J=0.8 \mathrm{~Hz}), 6.31(2 \mathrm{H}, \mathrm{q}, J=0.8 \mathrm{~Hz})$.

The Diels-Alder adduct 6. 2,5-Dimethylthiophene sulfone (1.1 g) and benzoquinone $(1.0 \mathrm{~g})$ were refluxed overnight in chloroform $(20 \mathrm{ml})$. The solvent was evaporated and cyclohexanecarbon tetrachloride $(2: 1,10 \mathrm{ml})$ was added and the black precipitate filtered off. Evap. oration and recrystallization from ethanol $(5 \mathrm{ml})$ gave the adduct 6 as yellow crystals, m.p. $59-60{ }^{\circ} \mathrm{C}, 0.8$ g. NMR $\left(\mathrm{CDCl}_{3}\right): \delta 1.82$ $(6 \mathrm{H}, \mathrm{s}), 3.52(2 \mathrm{H}, \mathrm{s}), 5.82(2 \mathrm{H}, \mathrm{s}), 6.72(2 \mathrm{H}, \mathrm{s})$. Evaporation of the solvent gave a yellow oil of impure adduct, contaminated by some benzoquinone and traces of 5,8-dimethylnaphtho- 
quinone. The highest peaks in the MS correspond to $\mathrm{M}-\mathrm{SO}_{2}$ and $\mathrm{M}-\mathrm{H}_{2} \mathrm{SO}_{2}$ (equal to naphthoquinone).

Acknowledgement. I would like to thank C.Sc. Marianne Hansen for the computer calculation of the NMR data for compound 3.

\section{REFERENCES}

1. Prochàzka, M. Collect. Czech. Chem. Commun. 30 (1965) 1158.

2. Bailey, W. J. and Cummins, E. W. J. Amer. Chem. Soc. 76 (1954) 1932, 1936.

3. Melles, J. L. and Backer, H. J. Rec. Trav. Chim. Pays-Bas 72 (1953) 491.

4. Melles, J. L. and Backer, H. J. Rec. Trav. Chim. Pays-Bas 72 (1953) 314.

5. O'Brien, D. F. and Gates Jr., J. W. J. Org. Chem. 30 (1965) 2593.

6. Reinhoudt, D. N., Smael, P., van Tilborg, W. J. M. and Visser, J. P. Tetrahedron Lett. (1973) 3755 .

7. Vesely, V., Sturza, F., Olejńiček, H. and Rein, H. Collect. Czech. Chem. Commun. 1 (1929) 493.

8. Bendz, G. Acta Chem. Scand. 5 (1951) 489.

9. Arbuzov, B. A. and Specterman, S. M. Trans. Kirov Inst. Chem. Tech. Kazan No. 8 (1940) 24; Chem. Abstr. 35 (1941) 2498.

10. Fierz-David, H. E., Blangey, $L$. and von Krannichfeldt, W. Helv. Chim. Acta 30 (1947) 816.

11. Lepage, Y. Bull. Soc. Chim. Fr. (1963) 2019.

12. Fieser, L. F. and Heyman, H. J. Amer. Chem. Soc. 64 (1942) 376.

13. Burnett, A. R. and Thomson, R. H. J. Chem. Soc. $C$ (1967) 2100.

Received August 29, 1975. 